\title{
Investigation of a new helical flow distributor design to extract thermal energy from hot water storage tanks
}

\author{
András Zachár* \\ Institute of Informatics, College of Dunaújváros, Táncsics M. u. 1., Dunaújváros, Hungary
}

\section{A R T I C L E I N F O}

\section{Article history:}

Received 19 May 2014

Received in revised form 21 September 2014

Accepted 24 September 2014

Available online 19 October 2014

\section{Keywords:}

Temperature stratification

Heat exchanger coil

Flow distributor

Entrainment phenomenon

\begin{abstract}
A B S T R A C T
Unsteady heat transfer process and the developed flow and temperature field inside hot water storage tanks have been studied with a helical tube-in-tube flow distributor. The primary purpose of the study is to improve the temperature stratification in hot water storage tanks operated with coiled-tube heat exchangers. The investigated operating mode is the extraction of thermal energy from hot water storage tanks. The studied flow distributor consists of two helically coiled pipes. The inner pipe is a common helically coiled tube heat exchanger and the outer pipe is a helically coiled flow distributor which separates the colder water from the significantly hotter bulk fluid of the tank to decrease the entrainment effect induced by natural convection. The flow distributor drives the cooling tank fluid to a helical flow path along the tube axis which induces additional secondary flow pattern in planes normal to the main flow direction over the outer surface of the inner coiled tube. Different inlet temperatures have been investigated to describe the impact for the developed velocity and temperature field. Comparison of the flow and temperature fields of hot water storage tank with common helical tube and the tube-in-tube flow distributor configuration are discussed. Numerical calculations have been carried out to examine different flow and temperature fields in laminar flow regimes. The proposed helical flow distributor ensures a highly stratified temperature field of storage tanks operating with helically coiled heat exchangers. In addition to this the suggested flow distributor geometry makes it possible to apply different heat transfer enhancement tools like spiral tape inserts, different kind of corrugations further improve if it is possible the poor outer side heat transfer rate of common helically coiled tube heat exchangers.
\end{abstract}

(c) 2014 Elsevier Ltd. All rights reserved.

\section{Introduction}

Temperature stratification is an important phenomenon of several different area of thermal fluid engineering and other non engineering fields of natural science like marine biology. Temperature stratification can be useful or less useful or even in some cases a dangerous phenomenon depending on the thermo hydraulic application. For example temperature stratification is an important factor that affects significantly the nutrient dynamics in the North Sea as studied by Warrach [1]. Temperature stratification has a significant impact on the vertical transport of nutrients investigated by Ruardij et al. [2]. Local temperature stratification can increase the fatigue of pipelines and serious mechanical damages such as cracks and plastic deformations due to excessive thermal stress caused by thermal stratification have been experienced in several nuclear power plants reported by Kang et al. [3]. Periodic occurrences of thermal transients lead to fatigue and may induce undesirable

\footnotetext{
* Tel.: +36 25551 618; fax: +36 25551231.

E-mail addresses: zachar.andras@mail.duf.hu, zachar.andras@gek.szie.hu
}

failures and deformations to the piping as studied by Rezende et al. [4]. Kweon et al. [5] has studied parameters which have significant effect on the fatigue of different structural elements of a piping system. These parameters are the boundary layer thickness, temperature difference, stratification length, wall thickness, inner diameter and material properties on peak temperature and peak stress intensity due to nonlinear temperature distribution of thermal stratification in a pipe cross-section. It is also important to note that the temperature stratification can increase the possibility of earlier boiling of dangerous fluids inside waste fluid containers. The reason behind this process is that the upper region of the waste or dangerous fluid container became hotter because of the stratification process and the boiling start earlier. Some case the earlier boiling can lead to an emergency situation.

In the other hand temperature stratification is an important and useful physical phenomenon of hot water storage tanks, especially in solar systems (Duffie and Beckman [6]). The thermal efficiency of a hot water solar system with a thermally stratified storage tank can be significantly improved in comparison to a system operating with a fully mixed tank investigated by Hollands and Lightstone 


\begin{tabular}{|c|c|c|c|}
\hline \multicolumn{4}{|c|}{ Nomenclature } \\
\hline$c_{P}(T)$ & $\begin{array}{l}\text { temperature dependent specific heat function of the } \\
\text { fluid }\left(\mathrm{J} \mathrm{kg}^{-1} \mathrm{~K}^{-1}\right)\end{array}$ & $T_{\text {tank }}$ & $\begin{array}{l}\text { initial temperature of the water inside the storage tank } \\
\left({ }^{\circ} \mathrm{C}\right)\end{array}$ \\
\hline$d_{c}, d_{\text {tank }}$ & diameter of the coil and of the tank (m) & $T_{\text {in }}, T_{\text {out }}$ & area averaged inlet/outlet temperature $\left({ }^{\circ} \mathrm{C}\right)$ \\
\hline $\begin{array}{l}d_{\text {in }}, d_{\text {out }} \\
d_{s}\end{array}$ & $\begin{array}{l}\text { inner and outer side diameter of the coiled pipe }(\mathrm{m}) \\
\text { inner side diameter of the helical flow distributor }(\mathrm{m})\end{array}$ & & $\begin{array}{l}\text { mass-flow averaged mean temperature of the fluid at a } \\
\text { specific cross section }\left({ }^{\circ} \mathrm{C}\right)\end{array}$ \\
\hline$d_{\text {gap }}$ & $\begin{array}{l}\text { distance between the inner surface of the helical flow } \\
\text { distributor and outer surface of the coil (m) }\end{array}$ & $T_{w}$ & $\begin{array}{l}\text { area averaged wall temperature at a specific cross } \\
\text { section of coiled tube }\left({ }^{\circ} \mathrm{C}\right)\end{array}$ \\
\hline De & Dean number $\left(=\operatorname{Re}\left(d_{i n} / d_{c}\right)^{0.5}\right)$ & \multirow{2}{*}{\multicolumn{2}{|c|}{$\begin{array}{l}U_{1}(x, y, z, t), U_{2}(x, y, z, t), U_{3}(x, y, z, t) \text { velocity component functions } \\
\text { into the three possible directions }\left(\mathrm{m} \mathrm{s}^{-1}\right)\end{array}$}} \\
\hline$h_{i}$ & inside heat transfer coefficient ( $\mathrm{W} \mathrm{m} \mathrm{m}^{-2} \mathrm{~K}^{-1}$ ) & & \\
\hline $\begin{array}{l}\mathrm{H}_{\text {tank }} \\
N u_{i}\end{array}$ & $\begin{array}{l}\text { height of the tank (m) } \\
\text { inner side Nusselt number }\left(h_{i} d_{i n} / k\right)\end{array}$ & $V_{\text {avg }}$ & area averaged velocity $\left(\mathrm{m} \mathrm{s}^{-1}\right)$ \\
\hline & helical pitch of the studied coils (m) & \multicolumn{2}{|c|}{ Greek symbols } \\
\hline \multicolumn{2}{|c|}{$P(x, y, z, t)$ function of the pressure field $(\mathrm{Pa})$} & \multirow[t]{2}{*}{$\eta(T)$} & temperature dependent dynamic viscosity function of \\
\hline $\operatorname{Pr}$ & Prandtl number $\left(=c_{p} \eta / \lambda\right)$ & & the fluid $\left(\mathrm{N} \mathrm{s} \mathrm{m}^{-2}\right)$ \\
\hline$q_{w}$ & $\begin{array}{l}\text { area averaged wall heat flux at a specific cross section } \\
\left(\mathrm{W} \mathrm{m} \mathrm{m}^{-2}\right)\end{array}$ & $\lambda(T)$ & $\begin{array}{l}\text { temperature dependent thermal conductivity function } \\
\text { of the fluid }\left(\mathrm{W} \mathrm{m}^{-1} \mathrm{~K}^{-1}\right)\end{array}$ \\
\hline$Q_{\text {in }}$ & tube side inlet mass flow rate $\left(\mathrm{kg} \mathrm{s}^{-1}\right)$ & $\rho(T)$ & temperature dependent density function of the fluid \\
\hline $\operatorname{Re}$ & Reynolds number $\left(=\rho V_{a v g} d_{i n} / \eta\right)$ & & $\left(\mathrm{kg} \mathrm{m}^{-3}\right)$ \\
\hline $\begin{array}{l}x, y, z \\
t\end{array}$ & $\begin{array}{l}\text { Cartesian coordinates }(\mathrm{m}) \\
\text { time }(\mathrm{s})\end{array}$ & $\phi$ & $\begin{array}{l}\text { angular coordinate normal to the tube cross section (ra- } \\
\text { dian) }\end{array}$ \\
\hline$T(x, y, z$ & t) temperature function of the water inside the heat ex & $\delta$ & curvature ratio $\left(=d_{i n} / d_{c}\right)$ \\
\hline
\end{tabular}

[7], Kleinbach et al. [8]. Many authors investigated experimentally and numerically several different aspect of the temperature stratification of different fluids inside different kind of enclosures. Numerical study of transient mixed convection in a cylindrical cavity has been carried out by Bouhdjar et al. [9]. Mo and Miyatake [10] investigated numerically the transient turbulent flow field in a thermally stratified thermal storage water tank. Transient natural convection from a finned surface for thermal storage has been studied by Benmadda and Lacroix [11]. The effect of inlet geometry on stratification in thermal energy storage has been investigated numerically by Ghajar and Zurigat [12]. Davidson and Adams [13] examined experimentally several kinds of stratification manifolds for solar water heating. Experimental analysis of a domestic electric hot water storage tank in dynamic operation mode has been carried out by Fernandez-Seara et al. [14]. Altuntop et al. [15] investigated the effect of water inlet velocity on thermal stratification in a mantled hot water storage tank.

Helically coiled-tube heat exchangers are one of the most common equipment found in many industrial applications ranging from solar energy applications, nuclear power production, chemical and food industries, environmental engineering, and many other fields of engineering. The inner side heat transfer rate of helically coiled tube heat exchangers is significantly larger because of the secondary flow pattern in planes normal to the main flow than in straight pipes. Several studies have been conducted to analyze the heat transfer rate of coiled heat exchangers in laminar and turbulent flow regimes (Zeng et al. [16], Lin and Ebadian [17]). Many authors investigated experimentally the turbulent heat transfer in helical pipes (Kalb and Seader [18]). Bozzoli et al. [19] estimated the local heat-transfer coefficient in the laminar flow regime in coiled tubes. The local peripheral distribution of the heat transfer intensity has been found strongly non uniform in case of highly viscous working fluids. Performance of a vertical helical coil heat exchanger has been studied by Fernandez-Seara et al. [20]. Numerical and experimental investigations have been carried out to evaluate the heat transfer performance of the studied helical coil. The shell-side thermal performances of heat exchangers with helical tube coils have been evaluated by Geniæ et al. [21]. It is well known that a helical heat exchanger coil submersed in any kind of fluid (water, oil, air, ...) develops a strongly mixed temperature field inside a closed enclosure. An additional flow distributor is needed to modify somehow the buoyancy induced flow which destroys the temperature stratification of the fluid inside the enclosure.

According to the author knowledge only a bell shaped flow distributor design which covers the helical coil from the top and outer side is invented to drive the heated fluid to the upper portion of a storage enclosure, but it can only be used for a heat charging process and not for a heat removal (discharge) process. This study is a natural continuation of the work published by Zachár [22] where a different geometrical construction has been investigated to heat up the tank fluid. Basic aim of this study is to propose, present and investigate a tube-in-tube helical flow distributor design to improve temperature stratification of solar hot water storage tanks operated by helically coiled tube heat exchangers to extract thermal energy more efficiently from the storage tank. Fig. 1 shows the basic geometrical arrangements and dimensions of the studied heat exchanger coil with the investigated flow distributor and the basic operating mode indicated by the additional arrows.

\section{Mathematical formulation}

This section provides the basic equations that must be solved to describe the velocity field and the temperature distribution inside the heat exchanger coil, the helical flow distributor and the storage tank. The physical problem is generally an unsteady, three dimensional flow configuration. The momentum equation of the fluid is based on the three dimensional Navier-Stokes equations. A SIMPLE like method is applied to solve the momentum and continuity equations. The dependent variables that describe the present flow situation are the temperature, $T$, velocity components $U_{i}$ in the $x, y$ and $z$ directions respectively and the pressure field $P$.

\subsection{Conservation equations}

The following set of partial differential equations for $U_{1}, U_{2}, U_{3}, P$ and $T$ as a functions of $x, y, z, t$ describes the flow and temperature field inside a helically coiled heat exchanger and a storage enclosure. The conservation equations are formulated in the 


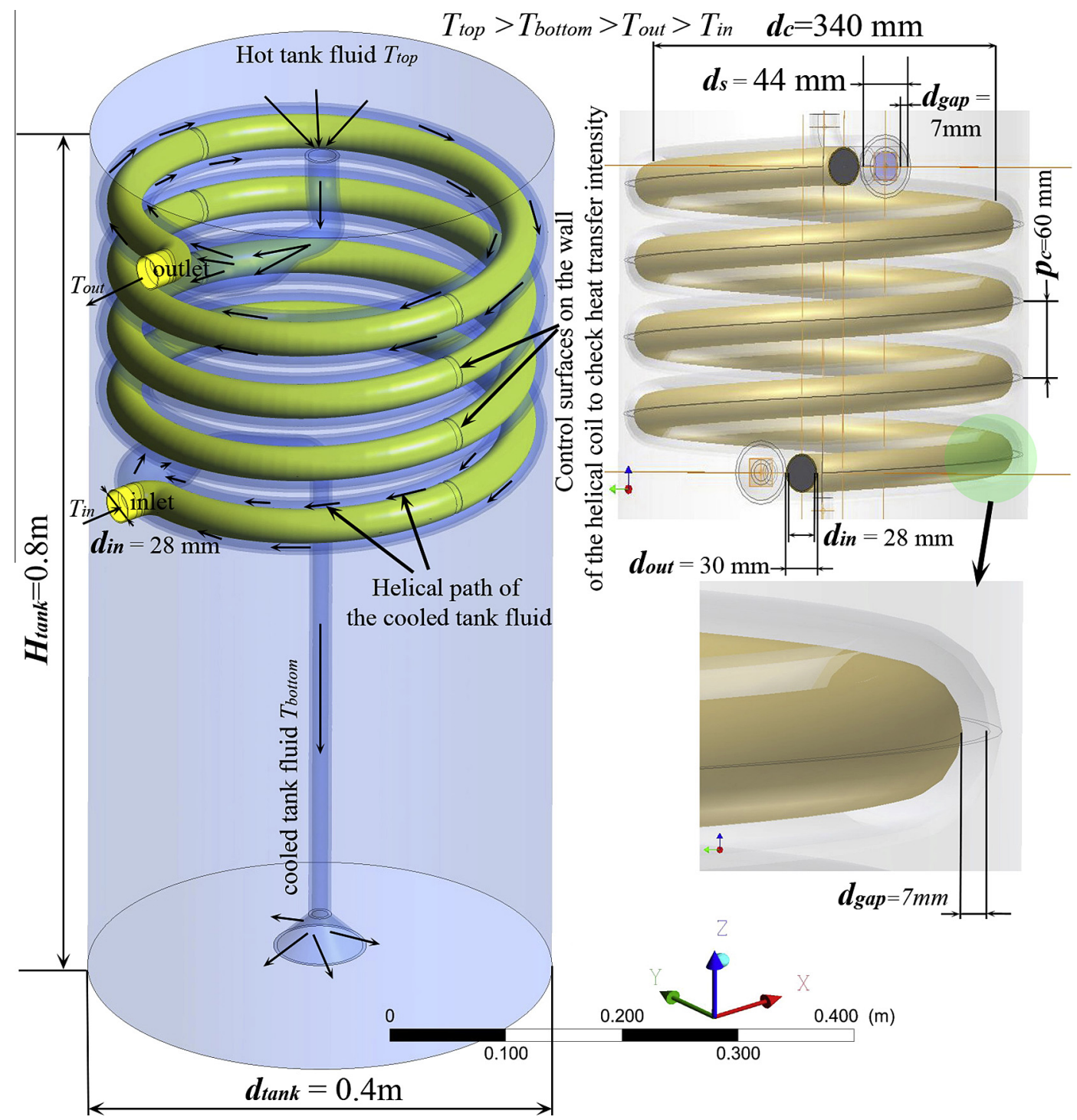

Fig. 1. Schematic figure of the studied flow distributor (FD I) with the coiled tube heat exchanger (Coil III) in a cylindrical enclosure.

Cartesian coordinate system because the applied flow solver (Ansys CFX 11.0) uses the Cartesian system to formulate the conservation equations for all quantities (vector $U_{i}$ and scalar $T, P)$. Description of the entire geometry of the studied problem is incorporated into the generated unstructured numerical grid.

\subsubsection{Continuity equation}

The continuity equation is formulated in the following manner in Cartesian coordinate system with tensor notation

$\frac{\partial}{\partial t}(\rho)+\frac{\partial}{\partial x_{i}}\left(\rho U_{i}\right)=0$

\subsubsection{Momentum equations}

The following equation system is the representation of the momentum equations in Cartesian coordinate system where $i$, $j \in\{1,2,3\}$,

$\frac{\partial}{\partial t}\left(\rho U_{j}\right)+\frac{\partial}{\partial x_{i}}\left(\rho U_{j} U_{i}\right)=-\frac{\partial P}{\partial x_{j}}+\frac{\partial}{\partial x_{i}}\left(\eta\left(\frac{\partial U_{j}}{\partial x_{i}}\right)\right)$

$\eta$ is the dynamic viscosity and $\rho$ is the density of the working fluid.

\subsubsection{Heat transport equation}

The following form of the energy equation is solved to calculate the developed temperature field of the studied flow process

$\frac{\partial}{\partial t}\left(\rho c_{p} T\right)+\frac{\partial}{\partial x_{i}}\left(\rho c_{p} U_{i} T\right)=\frac{\partial}{\partial x_{i}}\left(\lambda\left(\frac{\partial T}{\partial x_{i}}\right)\right)$

where $\lambda$ is the thermal conductivity and $c_{p}$ is the specific heat of the fluid at constant pressure. The transport equations have been formulated in a conservative form which is more suitable for numerical treatment. Temperature dependency of different physical properties $\left(\lambda, c_{p}, \eta, \rho\right)$ of the working fluid has been incorporated to improve the accuracy of the calculations. Following interpolation polynomials have been fitted to the available numerical data of the physical properties of the water used in the numerical calculations. The presented temperature dependent functions of the physical properties can only be used in the following temperature range $\left[0{ }^{\circ} \mathrm{C}, 90^{\circ} \mathrm{C}\right]$, outside this domain the values of the physical properties can be incorrect. 


$$
\begin{aligned}
& \rho(T)=998.25-0.123261 T-0.00131119 T^{2}-0.0000121406 T^{3} \\
& \eta(T)=0.00166167-0.0000410857 T+4.6480210^{-7} T^{2}-1.9055910^{-9} T^{3} \\
& c_{p}(T)=4222.62-0.694932 T+0.00624126 T^{2}+8.2944810^{-6} T^{3} \\
& \lambda(T)=0.568733+0.00196461 T-9.7785510^{-6} T^{2}+1.243210^{-8} T^{3}
\end{aligned}
$$

\subsection{Domain of discretization}

Fig. 1 shows the geometrical arrangement of the numerically studied helical coil, flow distributor, storage tank configuration (FD I) where the transparent view of the computational domain of the cylindrical storage tank, the helical flow distributor and the helically coiled tube heat exchanger can be seen. For better understanding of the relatively complex helical flow distributor geometry, Fig. 2 presents the flow distributor and heat exchanger in three different perspective views. Table 1 contains the geometrical parameters of the studied coils. The most important geometrical parameters of the investigated flow distributor - heat exchanger coil configuration can be seen in Table 2. The domain of the numerical computation consists of three separate calculation domain. Three separated domains were created embedded to each other for the numerical calculation of the inner flow, pipe and the flow distributor-storage tank. One of the applied grids seen in Fig. 3 is strongly non-uniform near the outer side wall of the helical tube and the inner side of the helical flow distributor to resolve the wall boundary effects. Fig. 3 shows different parts of the generated grid around the helical coil and the flow distributor inside a cylindrical storage tank. So called prismatic cells have been used on the outer

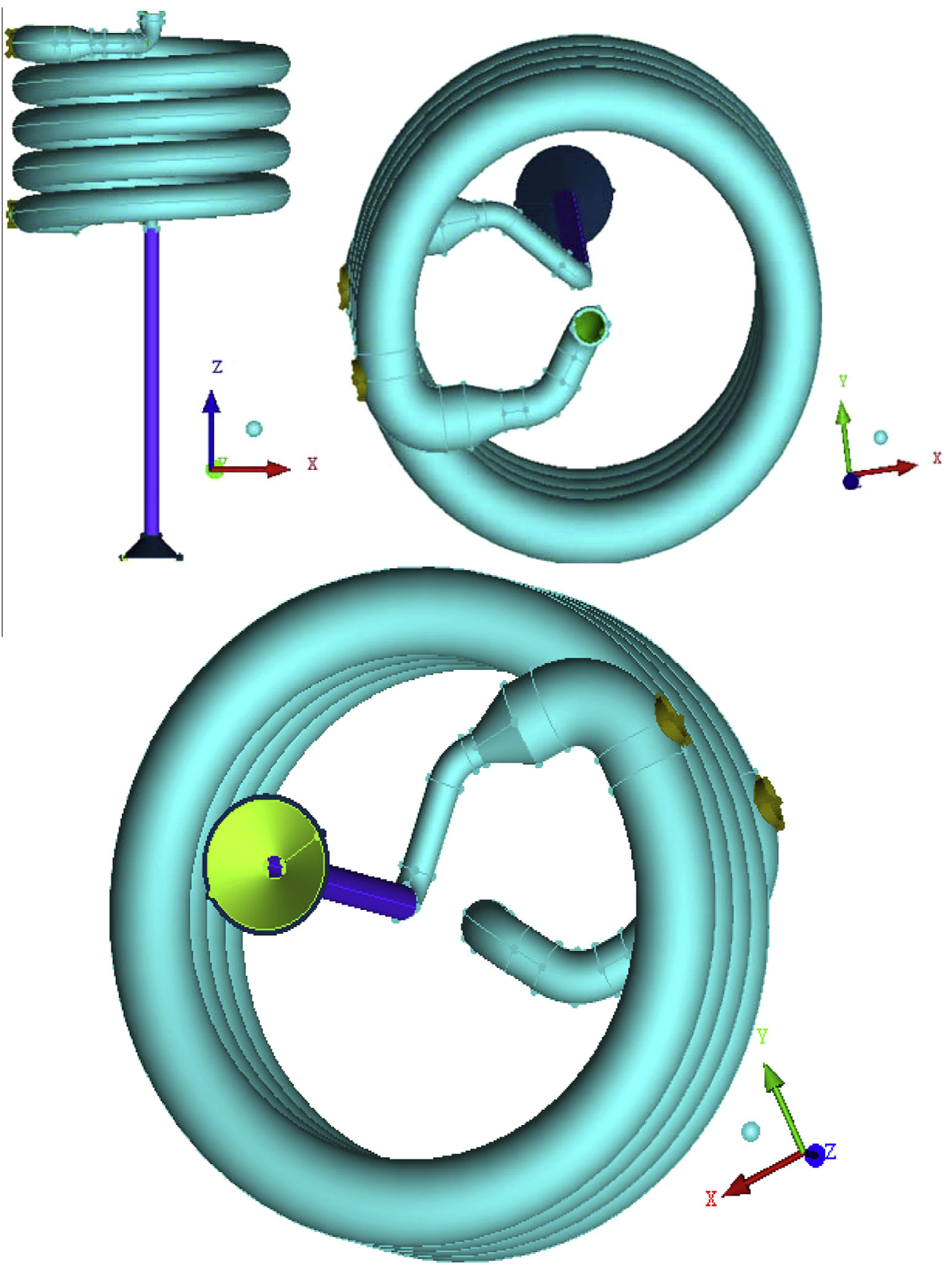

Fig. 2. Geometrical arrangement of the helical flow distributor and the heat exchanger coil. 
Table 1

Geometrical parameters of the studied coils.

\begin{tabular}{|c|c|c|c|c|c|c|c|}
\hline & $d_{c}[\mathrm{~mm}]$ & $d_{\text {in }}[\mathrm{mm}]$ & $d_{\text {out }}[\mathrm{mm}]$ & $p_{c}[\mathrm{~mm}]$ & Num. of turns & $\delta[-]$ & $p_{c} / d_{c}[-]$ \\
\hline Coil I Prabhanjan et al. [23] & 203 & 15.7 & 18.1 & 18.1 & 10 & 0.07733 & 0.08916 \\
\hline Coil II Prabhanjan et al. [24] & 203 & 11.5 & 13.5 & 40.5 & 9.5 & 0.05665 & 0.1995 \\
\hline Coil III, $d_{\text {tank }}=400 \mathrm{~mm}$ & 340 & 28 & 30 & 60 & 4 & 0.08235 & 0.17647 \\
\hline
\end{tabular}

Table 2

Geometrical parameters of the studied flow distributor with the applied coil.

\begin{tabular}{lllll}
\hline $\begin{array}{l}\text { Flow } \\
\text { distributor }\end{array}$ & Studied coil & $\begin{array}{l}d_{\text {gap }} \\
{[\mathrm{mm}]}\end{array}$ & $\begin{array}{l}d_{s} \\
{[\mathrm{~mm}]}\end{array}$ & $\begin{array}{l}H_{\text {tank }} \\
{[\mathrm{mm}]}\end{array}$ \\
\hline FD I. & $\begin{array}{l}\text { Coil III, } \\
d_{\text {tank }}=400 \mathrm{~mm}\end{array}$ & 7 & 44 & 800 \\
& & & &
\end{tabular}

surface of the helical pipes and on the inner surface of the helical flow distributor inside the flow distributor-storage tank domain. Nineteen layers of prismatic cells have been generated with 1.15 increment factor to discretize the near wall boundary of the outer side of the helical pipe and the inner side of the helical flow distributor. A boundary layer grid has also been generated to the inner side flow domain from the inner wall of the helical tube which consists of thirteen layers of prismatic cells. The inner and outer side boundary regions of the solid tube wall (made of cooper) domain are created with five layers of prismatic cells. A careful check for the grid-independence of the numerical solution has been made to ensure the accuracy and validity of the numerical scheme. The total sum of finite volumes of the three separately generated grids is 32794016 finite volumes.

\subsection{Initial and boundary conditions}

The initial velocity field is zero and the initial state of the temperature field to be considered is constant everywhere inside the calculation domain. Constant mass flow is assumed at the inlet position of the heat exchanger coil. The gradient of the velocity profile and of the temperature field is assumed to be zero at the outlet end. An adiabatic boundary condition (fully insulated) is specified for the outer wall of the storage tank and the wall of the helical flow distributor.

\subsection{Numerical solution of the transport equations}

The corresponding transport equations with the appropriate boundary conditions have been solved a commercially available CFD code (Ansys CFX 11.0). A "High Resolution Up-Wind like" scheme is used to discretize the convection term in the transport equations. The resulting large linear set of equations is solved with an algebraic multi-grid solver. The applied grids for the different geometries have been generated with the ICEM CFD grid generator.

\subsection{Calculation of the dimensionless quantities}

Representing the numerically calculated results and creating the quantitative evaluation of heat transport process of the coiled tubes and the studied flow distributor, the following dimensional and non-dimensional quantities have been used. In case of Reynolds number calculations the value of the density and dynamic viscosity $(\rho, \eta)$ of the working fluids have been calculated by averaging for the entire fluid volume. The thermal conductivity of the

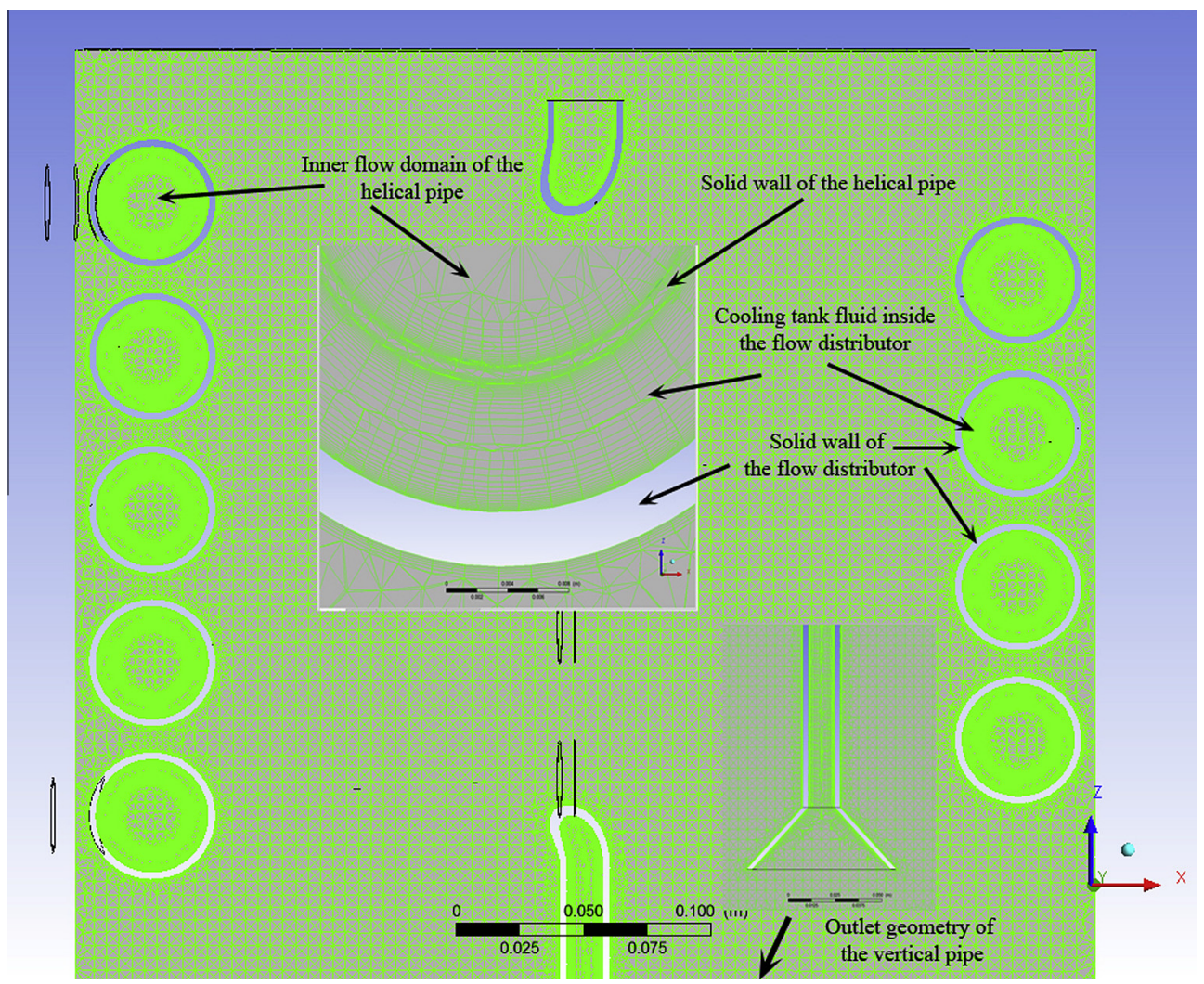

Fig. 3. A vertical cross section of the grid used for the calculations. 
fluid $\left(k_{a v g}\right)$ has been calculated at a specific cross section. The wall heat flux and the wall temperature $\left(q_{w}, T_{w}\right)$ have been calculated between two nearby $(\approx 5 \mathrm{~mm})$ pre-specified cross sections of the tube on a cylindrical surface as can be seen in Figs. 1 and 4. The fluid bulk temperature has been calculated with mass flow averaging, where $\bar{v}$ is the fluid bulk velocity at the same cross section of the tube. The characteristic length has been specified as the inner or outer side diameter of the helical pipe depending on the side where the heat transport intensity is calculated.

$$
\begin{aligned}
& \operatorname{Re}=\frac{d_{\text {in }} \rho \bar{v}}{\eta}, \quad \mathrm{Nu}_{\text {out }}=\frac{d_{\text {out }} q_{w}}{k_{\text {avg }}\left(T_{w}-T_{m}\right)}, \quad \mathrm{Nu}_{\mathrm{ax}}=\frac{1}{n} \sum_{i=1}^{n} \mathrm{Nu}_{\text {out }, i}, \\
& q_{w}=\frac{1}{A_{\text {wall section }}} \iint_{A} q d A_{\text {wall section }}, \quad T_{w}=\frac{1}{A_{\text {wall section }}} \iint_{A} T d A_{\text {wall section }}, \\
& T_{m}=\frac{1}{\bar{v} A_{\text {cross section }}} \iint_{A} \bar{v} T d A_{\text {cross section }}
\end{aligned}
$$

Figs. 1 and 4 show the geometrical regions used to evaluate the physical properties, mass flow rates and averaged cross sectional temperature of the working fluids and the averaged local $(\phi=\pi / 2$, $3 \pi / 2,5 \pi / 2, \ldots)$ surface heat flux and temperature of the coiled tubes.

2.6. Validation of the numerical calculations with experimental results published in the literature in case of common helically coiled tube heat exchangers

This section contains a test of the validity of the entire numerical computation to ensure the physical reality of the calculation

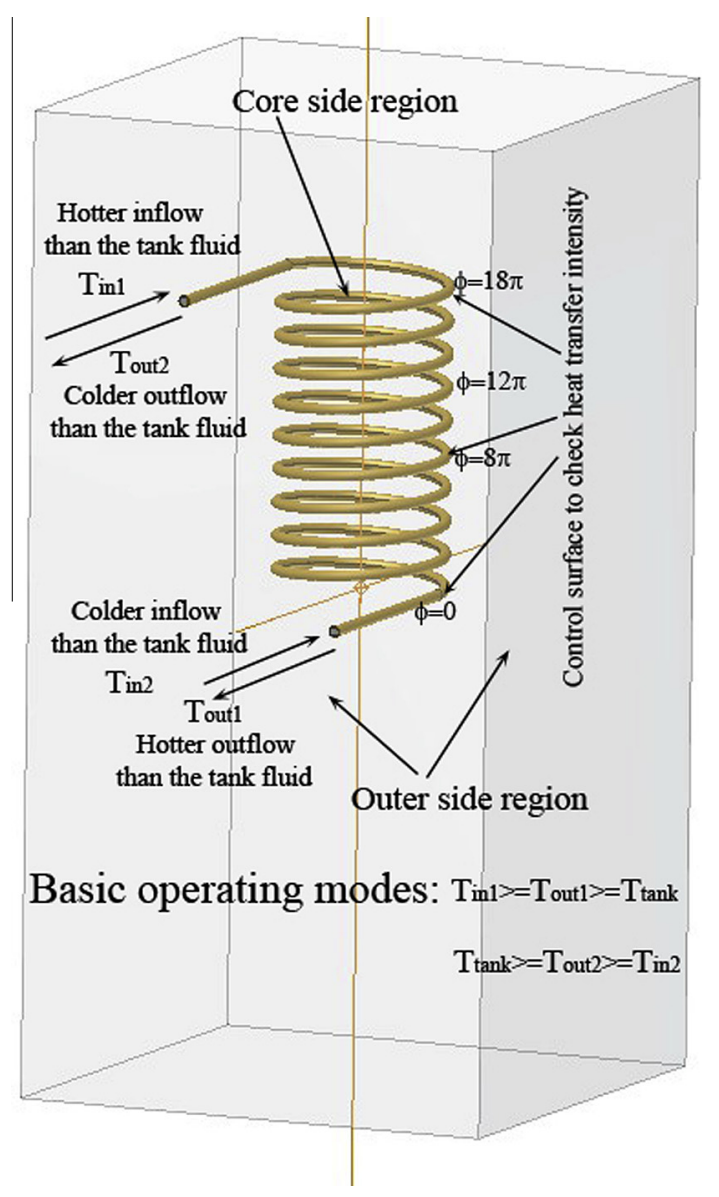

Fig. 4. Schematic figure of a coil-tank geometry used to validate the numerical calculations Prabhanjan et al. [24]. results. Fig. 4 contains a schematic figure of a rectangular tank and a helical coil investigated experimentally by Prabhanjan et al. [24]. The purpose of the investigation of this configuration was to validate the entire numerical computation what can be extended to the more complex geometry of the flow distributorcoiled tube-storage tank assembly. The possible operating modes (upper inlet: $T_{\text {in }}>T_{\text {out }}>T_{\text {tank }}$, lower inlet: $T_{\text {tank }}>T_{\text {out }}>T_{\text {in }}$ ) of the common helical coil-storage tank geometry can be also seen in Fig. 4. All of the necessary ingredients of the calculations (applied grid resolutions, temperature dependent physical properties of the water, boundary conditions, applicability of the laminar or turbulent modeling) are examined to extend the validity of the numerical investigations to a wider range of geometrical configurations of helically coiled tube heat exchangers with helical flow distributors. The following reasons ensure that the experimental setup is applicable for validating the tube-in-tube flow distributor configuration. (a): The helical coil with and without the flow distributor are buoyancy driven flow there is no forced convection flow outside the coil. (b): Both flow case is a boundary layer dominating flow (except the stratification or mixing process of tank fluid far from the coil surface) and the flow in the boundary layer is similar to each other and it is in a laminar flow state. (c): The driving force of the developed flow fields which is the temperature difference between the inner side and outer side working fluid is nearly equal in both flow case. d: There is only one significant difference between the validated and the numerically investigated geometry it is the flow over the outer side boundary layer of the helical coil. But this flow field contains slowly moving buoyancy driven fluid what can be adequately described by a sufficiently fine numerical grid.

Two different helical coil-storage tank geometries have been used to test the validity of the numerical calculations (Prabhanjan et al. [23,24]). Primarily the results of article [24] have been used to compare the numerical calculations with the experimental tests. The experimental setup is a rectangular container with dimensions $600 \times 600 \times 1200 \mathrm{~mm}$. It contains a helical coil with 9.5 turns and helical pitch $40.5 \mathrm{~mm}$. Outer diameter of the helical pipe was $13.5 \mathrm{~mm}$ the wall thickness was $1.0 \mathrm{~mm}$, and the helical diameter of the heat exchanger was $203 \mathrm{~mm}$. Temperature of the inlet water has been adjusted to $T_{i n}=19{ }^{\circ} \mathrm{C}$ and three different flow rates have been tested in the experiments $(0.1,0.15,0.2 \mathrm{~kg} / \mathrm{s})$. Temperature of the water inside the rectangular enclosure was kept constant $\left(75^{\circ} \mathrm{C}\right.$ or $\left.90^{\circ} \mathrm{C}\right)$ with built in electrical heaters. Geometrical arrangement of the experimental tests can be seen in Fig. 4. Numerical simulation of the experiments contains three different calculation domains, first one is the inner side of the heat exchanger coil filled with water, second one is a solid domain what is a cooper pipe, and the third one is the flow domain around the heat exchanger coil.

Outlet temperature of the heated water inside the coiled tube has been used to compare the calculation results with the published [24] experimental tests. The values of the $T_{\text {outlet exp }}$ are originated from Prabhanjan et al. [24, Fig. 3]. $T_{\text {tank }}$ is the temperature of the water around the coil in the experiments and also in the numerical calculations. $T_{\text {outlet calc } L}$ and $T_{\text {outlet calc } T}$ are the numerically calculated area averaged outlet temperature of the water flowing inside the studied coil in case of laminar and turbulent flow modeling. Table 3 shows a quantitative results of the comparison between the result of experimental tests presented by Prabhanjan et al. [24] and the numerically calculated results with laminar and turbulent flow modeling where the calculated outlet temperatures with laminar and turbulent flow modeling are compared to the experimentally collected outlet temperatures. The calculated results show an acceptable $<5 \%$ (in some cases a good $<2 \%$ ) agreement with the experimental data in case of the presented experiments. Interestingly the laminar flow computation gives a 
Table 3

Quantitative comparison of the different test configurations with the calculations results Relative error $\operatorname{err}_{L}, \operatorname{err}_{T}=100 \mathrm{abs}\left(\left(T_{\text {outlet exp }}-T_{\text {outlet calc }}\right) / T_{\text {outlet exp }}\right)[\%]$.

\begin{tabular}{llllllc}
\hline $\begin{array}{l}Q_{\text {in }} \\
{[\mathrm{kg} / \mathrm{s}]}\end{array}$ & $\begin{array}{l}T_{\text {tank }} \\
{\left[{ }^{\circ} \mathrm{C}\right]}\end{array}$ & $\begin{array}{l}T_{\text {outlet exp }} \\
{\left[{ }^{\circ} \mathrm{C}\right]}\end{array}$ & $\begin{array}{l}T_{\text {outlet calc } L} \\
{\left[{ }^{\circ} \mathrm{C}\right]}\end{array}$ & $\begin{array}{l}T_{\text {outlet calc }} \\
{\left[{ }^{\circ} \mathrm{C}\right]}\end{array}$ & $\begin{array}{l}\operatorname{err}_{L} \\
{[\%]}\end{array}$ & $\begin{array}{l}\operatorname{err}_{T} \\
{[\%]}\end{array}$ \\
\hline 0.1 & 75 & 43 & 43.72 & 45.23 & 1.67 & 5.18 \\
0.1 & 90 & 54 & 53.23 & 56.6 & 1.42 & 4.81 \\
0.15 & 75 & 37 & 38 & 38.78 & 2.7 & 4.81 \\
0.15 & 90 & 44 & 45.38 & 47.7 & 3.13 & 8.4 \\
0.2 & 75 & 31.5 & 34.39 & 34.8 & 9.17 & 10.47 \\
0.2 & 90 & 40 & 40.589 & 42.15 & 1.47 & 5.3 \\
\hline
\end{tabular}

slightly better agreement with the experimental test than the turbulent flow modeling (SST turbulent modeling) approach. The reason of this outcome is that the boundary layer is in a laminar flow state around the outer side of the helical pipe along the pipe axis. According to the different experimental formulas to predict the critical Reynolds number inside coiled tubes the flow state is in the turbulent flow regime with Reynolds numbers in the range of $11,000-25,500$ that is a low intensity (low-Reynolds) turbulent flow state. Further checks have been carried out to test the validity of the numerical computations with Coil I presented by Prabhanjan et al. [23]. In this case also the outlet temperature of the working fluid inside the coiled tube has been used to compare the result of the numerical computation with the experimental tests. The calculations show acceptable agreement with the experimental data.

\section{Results}

The investigated flow distributor geometry is a helically coiled tube-in-tube design that fully surrounds the outer surface of the coiled tube heat exchanger. Fig. 1 shows the studied flow distributor heat exchanger coil configuration (FD I) where the transparent view of the cylindrical storage tank, the helical flow distributor geometry, the helically coiled tube heat exchanger and the possible operating mode of the flow distributor can be seen.

Fig. 2 presents the flow distributor and the heat exchanger coil configuration without the storage tank in three different perspective views. The basic operating mode is when the buoyancy driven flow moves downward in a helical path to the vertical pipe what is located in the symmetry axis of the storage tank. The downward moving cooled fluid flow can be seen at the inlet of the collector pipe in Fig. 5. The hot tank fluid comes from the top region of the storage tank through a collector pipe. The velocity field in a vertical plane around the vertical distributor pipe at the bottom region of the tank has been presented in Fig. 6. The outlet of the vertical distributor pipe is located in the symmetry axis of the storage tank indicated by Fig. 6. This is an optimal position of the distributor pipe because the additionally induced swirling motion inside the storage tank can be diminished or significantly reduced with this arrangement. Local velocity field of the secondary flow induced by the colder surface of the helical coil has been shown in Fig. 7.

It is well known that, the transition from laminar to turbulent flow in curved pipes occur much higher critical Reynolds number $\left(R e_{c r i t}\right)$ than in straight pipes. The critical Reynolds number for smooth helical pipes can be estimated by the following formula found in Srinivasan et al. [25] $\operatorname{Re}_{\text {crit }}=2100(1+12 \sqrt{\delta})$. Applying this formula the value of the critical Reynolds number in the studied geometrical case is as follows:

$\delta=\frac{d_{\text {in }}}{d_{c}}=\frac{0.028}{0.34} \rightarrow \operatorname{Re}_{\text {crit }} \cong 9331$.

3.1. Unsteady investigation of the heat transfer process of the helical flow distributor and the temperature stratification of the storage tank

Basic aim of the unsteady investigation of the temperature field of the storage tank is to prove that the developing temperature field is in a well stratified state applying the helical flow distributor. For this reason two different flow cases have been studied using unsteady numerical simulation with flow distributor FD ICoil III configuration. Following initial and boundary values have been specified for the numerical calculations. Temperature of the inlet water was constant $\left(20^{\circ} \mathrm{C}\right)$, and the initial temperature of the water inside the cylindrical enclosure has been adjusted to $T_{\text {ini }}=\left(40^{\circ} \mathrm{C}, 60^{\circ} \mathrm{C}, 80^{\circ} \mathrm{C}\right)$ and the applied inlet flow rate of Coil III

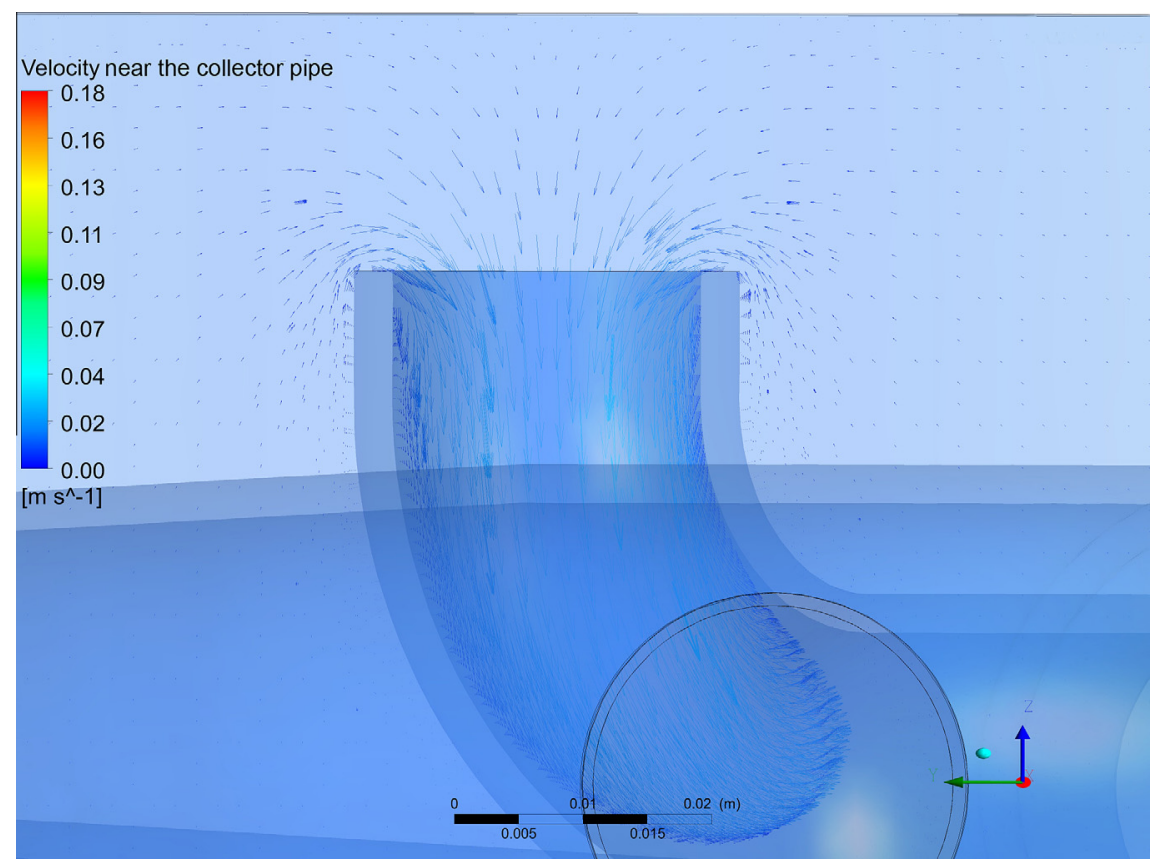

Fig. 5. Flow field near the inlet of the vertical collector pipe of the flow distributor. 


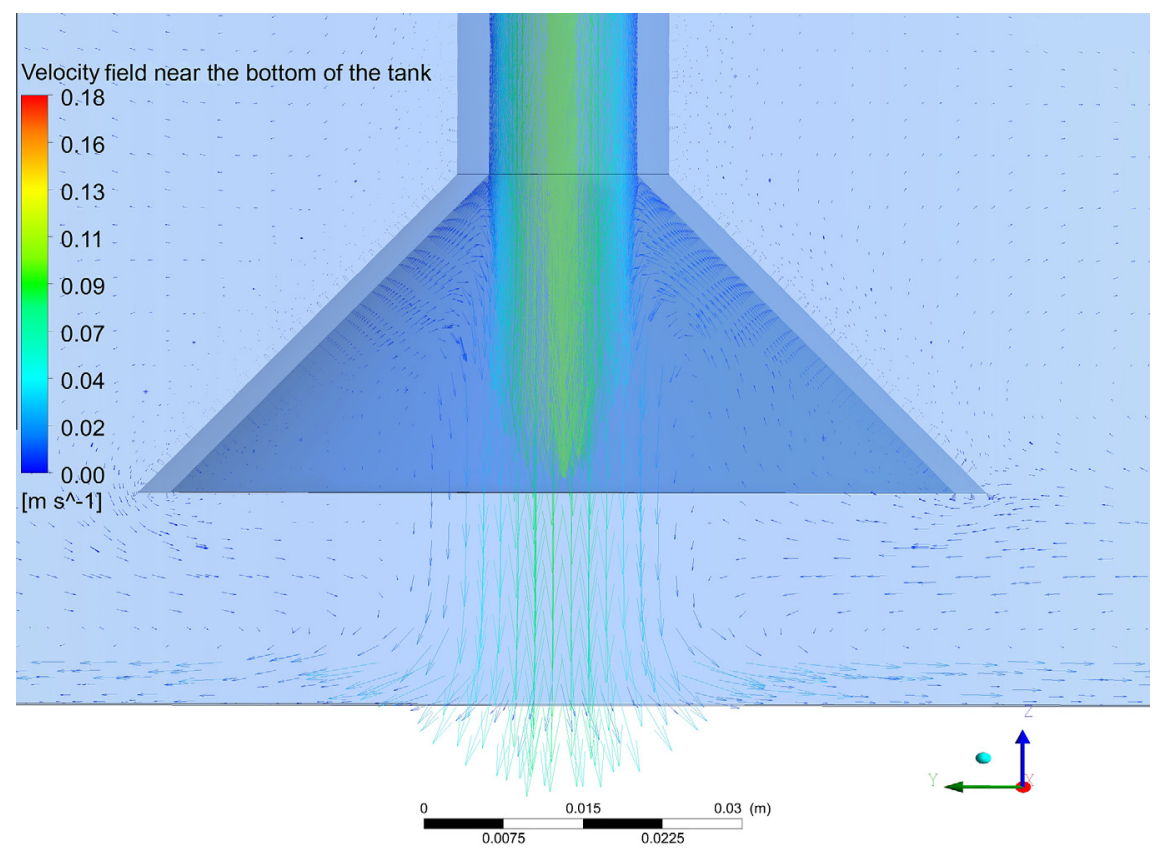

Fig. 6. Flow field around the outflow of the diffusor pipe near the bottom of the storage tank.

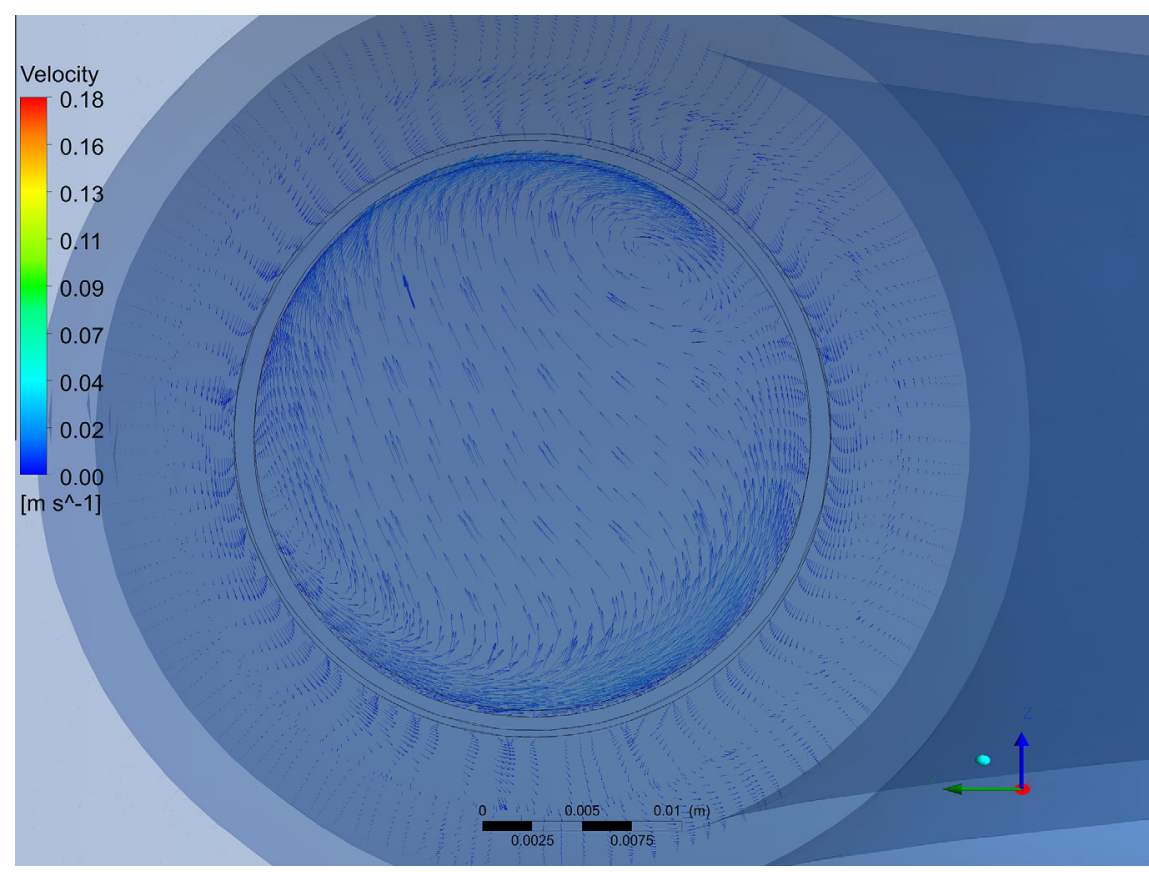

Fig. 7. Typical buoyancy induced velocity field over the coiled tube (Coil III) inside the flow distributor.

was $\left(m_{i n}=0.05 \mathrm{~kg} / \mathrm{s}\right)$. With this mass flow rate the flow field inside the coiled pipe is in a laminar flow state because the average inlet velocity is $v_{\text {in }}=4 \quad m_{\text {in }} /\left(\begin{array}{lllll}\rho & d_{\text {in }} & d_{\text {in }} & \pi\end{array}\right)=4 \quad 0.05 /\left(\begin{array}{llll}995 & 0.028 & 0.028\end{array}\right.$ $\pi)=0.0816 \mathrm{~m} / \mathrm{s}$ and from this value $\left(\operatorname{Re} \approx 2290<\operatorname{Re}_{\text {crit }} \approx 9331\right)$. The simulated physical time interval of the flow process was $205 \mathrm{~s}$ in case of $T_{i n i}=40^{\circ} \mathrm{C}$ and $150 \mathrm{~s}$ in case of $T_{i n i}=80^{\circ} \mathrm{C}$. The reason of this relatively small physical time interval was that the runtime of the numerical calculations takes more than two weeks to accomplish the necessary calculations simulating the 205 and $150 \mathrm{~s}$ flow process. But this time interval (approximately three minutes) is sufficiently enough to prove that the developing temperature field is an initial stage of a well stratified temperature distribution of the storage tank fluid. Figs. 8 and 9 show the contour plots of the vertical temperature distribution of the water inside the storage tank and the helical flow distributor at different time instances. The different temperature zones have been labeled and colored to see the time evolution of the vertical temperature distribution of the water. To evaluate the level of the temperature stratification a qualitative visual investigation has been carried out and the quality of the temperature stratification has not been studied from quantitative point of view. The final state of a long term heat discharging process is strongly dependent on the shape and geometry of the outlet of the vertical pipe what currently has not been studied. For this reason there is no point into measure the 


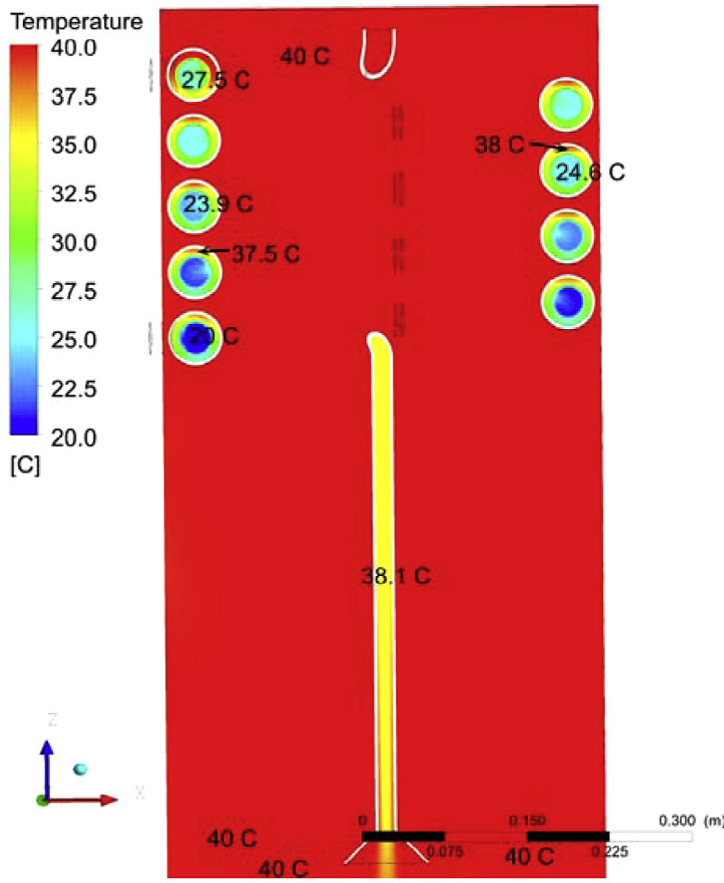

$t=75 \mathrm{~s}$

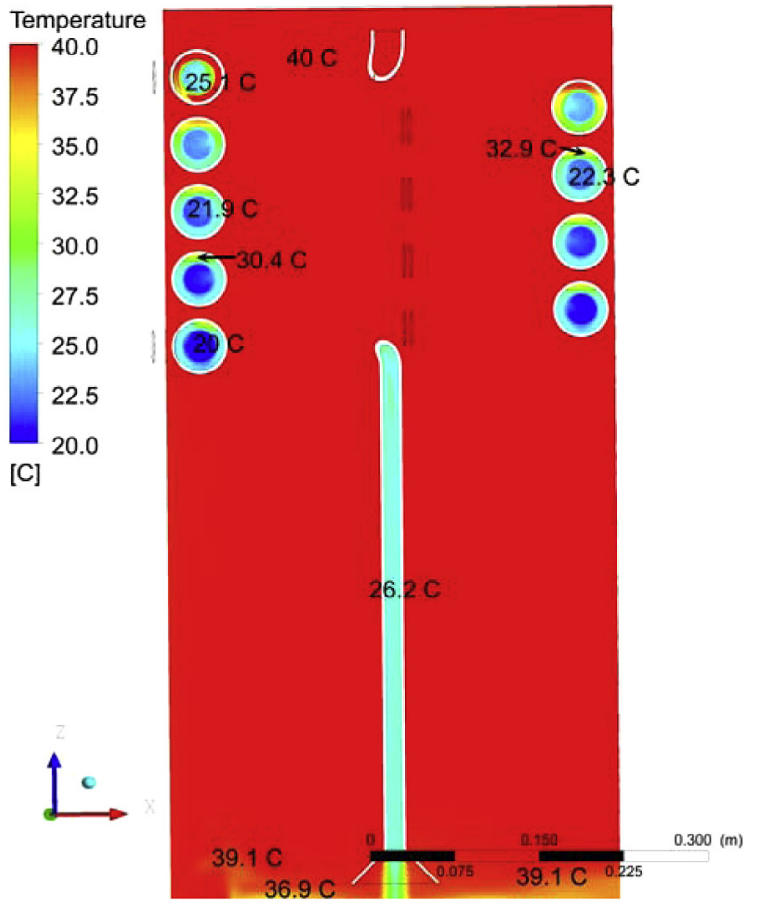

$t=175 \mathrm{~s}$

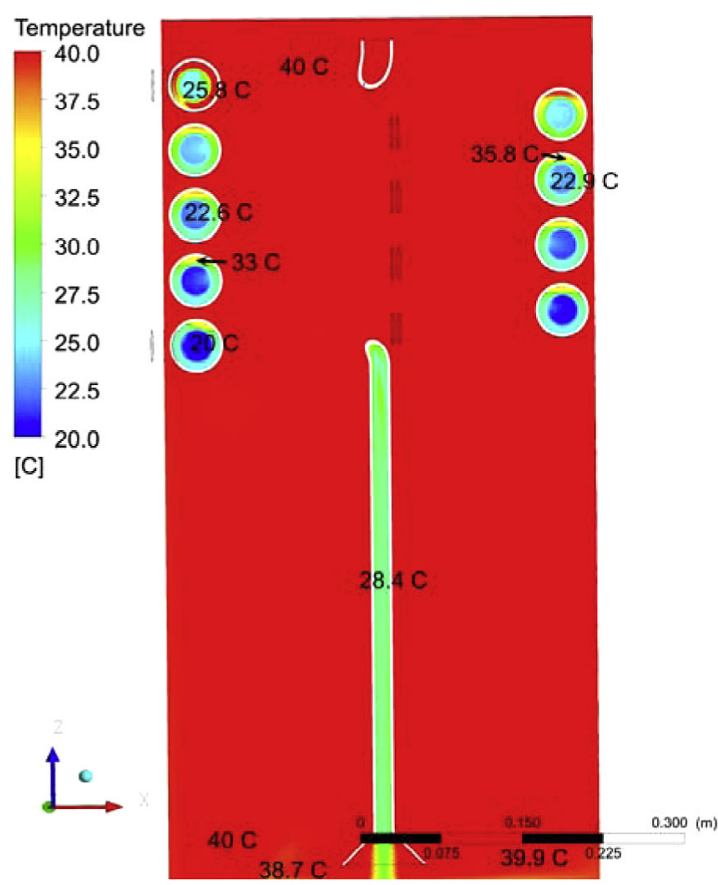

$t=125 \mathrm{~s}$

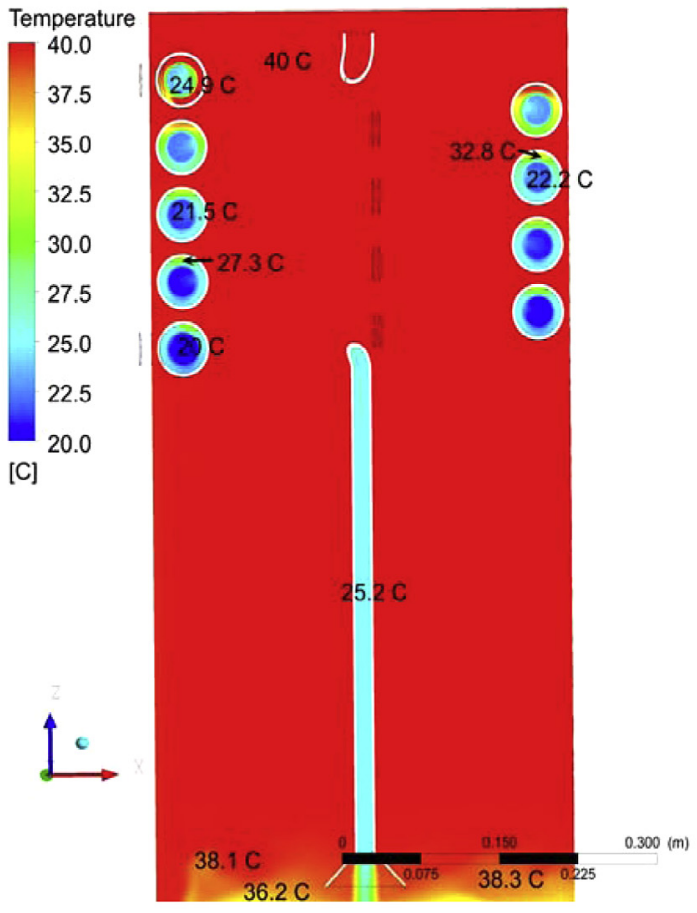

$t=205 \mathrm{~s}$

Fig. 8. Temperature contours at different time instances inside the storage tank and the flow distributor (FD I in case of $T_{i n}=20{ }^{\circ} \mathrm{C}$ and $T_{i n i}=40{ }^{\circ} \mathrm{C}$ ).

quantitative values of the stratification level with the mix number or any other quantitative measure of the temperature stratification. Contour plots of the vertical temperature distribution of the water in case of $T_{i n i}=40^{\circ} \mathrm{C}$ flow process has been indicated in Fig. 8 at four successive time instances. The temperature of the downward moving cooled fluid inside the vertical pipe can be clearly seen and the temperature value has been indicated near the outlet of the vertical distributor pipe. Temperature of the cooling fluid has also been indicated inside the helical coil and the flow distributor at the last turn ( $\phi=4 \pi$, uppermost circle in the left side column of the circles in each figure) and the first turn ( $\phi=0$, first circle from the bottom in the left side column of the circles in each figure). It can be seen from the series of the presented temperature values inside the vertical pipe and the flow distributor that nearly three minutes needed to develop a quasi steady state temperature field inside the flow distributor after starting the heat 


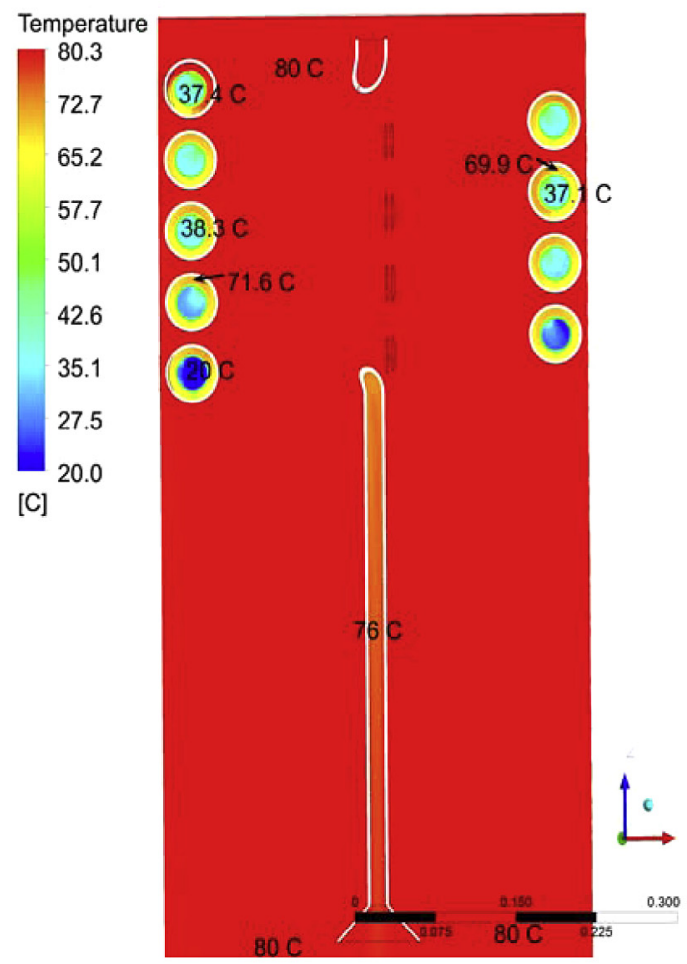

$t=25 \mathrm{~s}$

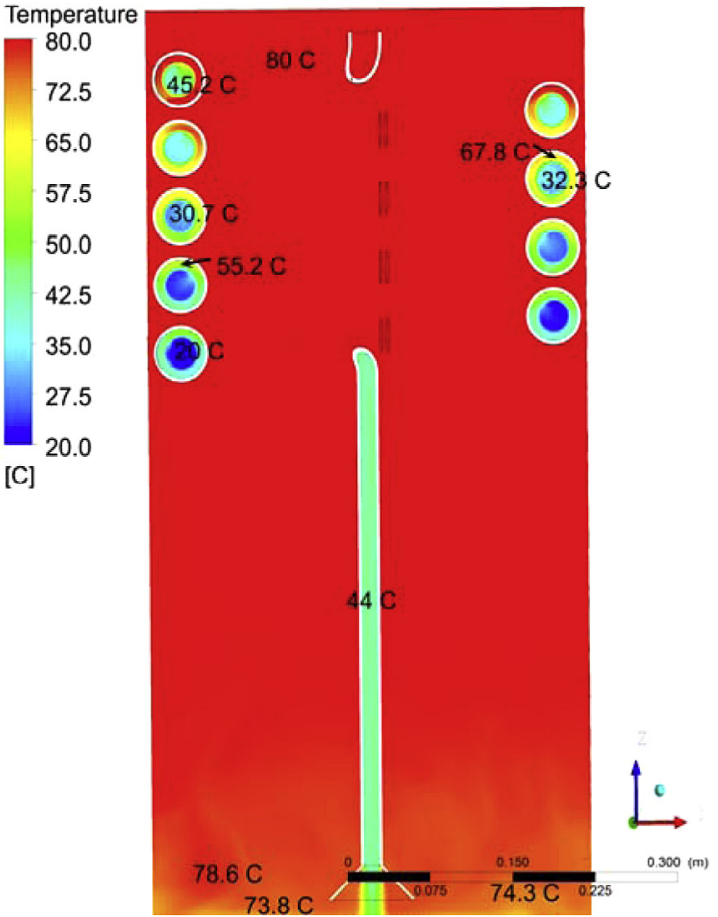

$t=125 \mathrm{~s}$

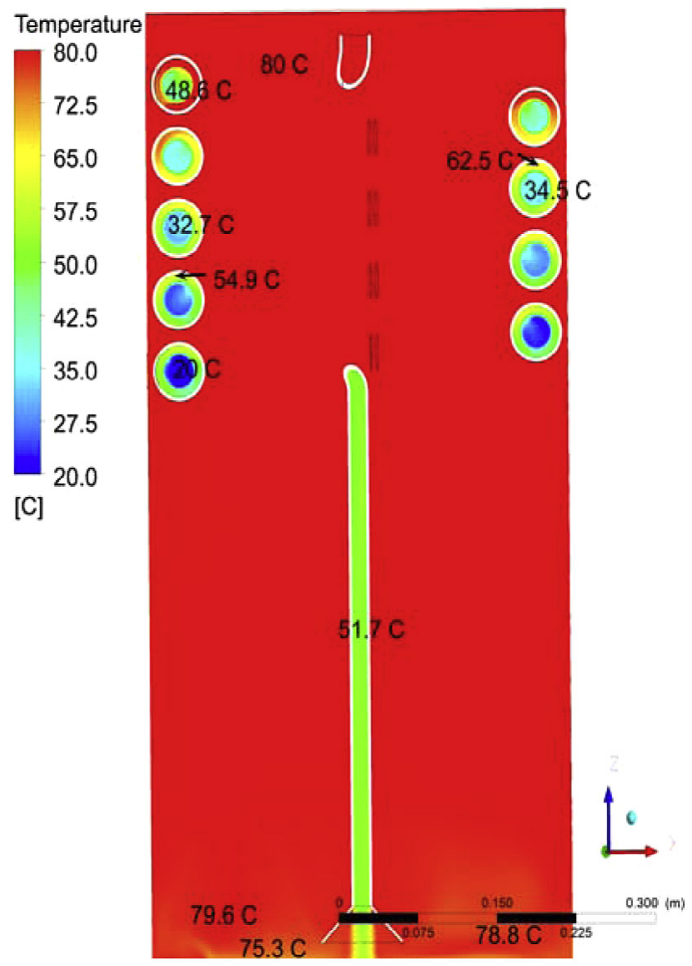

$t=75 \mathrm{~s}$

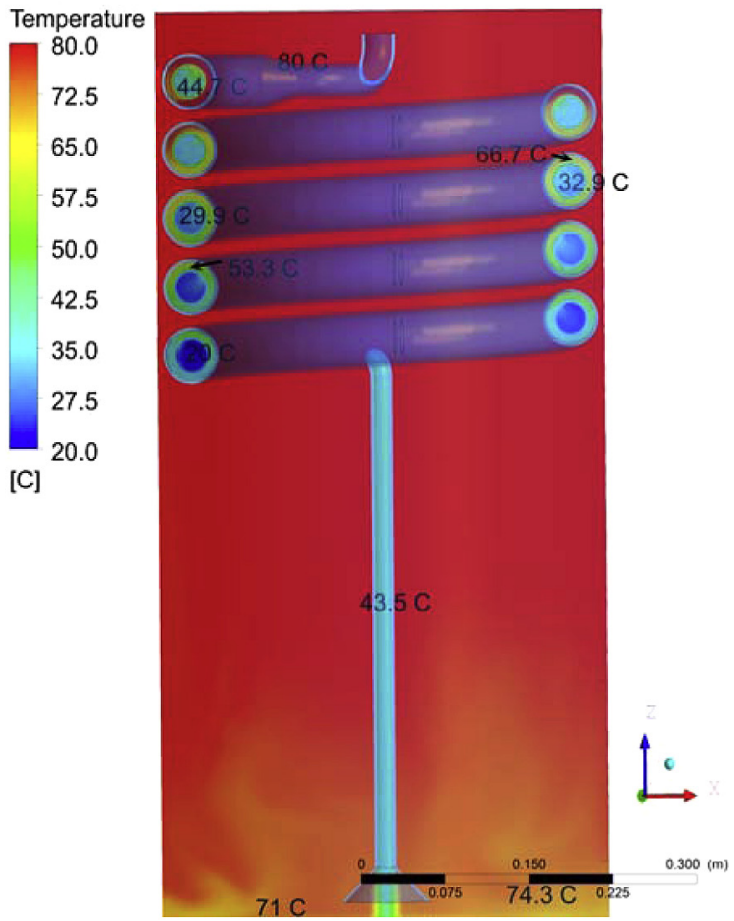

$t=155 \mathrm{~s}$

Fig. 9. Temperature contours at different time instances inside the storage tank and the flow distributor $\left(\mathrm{FD} \mathrm{I}\right.$ in case of $T_{i n}=20^{\circ} \mathrm{C}$ and $T_{i n i}=80{ }^{\circ} \mathrm{C}$ ).

discharging process. Outside the flow distributor a slowly developing stratified temperature field can be seen at the successive time instances of Fig. 8. Similar considerations can be drawn for the other flow case $T_{\text {in }}=80^{\circ} \mathrm{C}$ what can be seen in Fig. 9. It can be concluded that the suggested tube-in-tube helical flow distributor configuration can develop a well stratified temperature field inside any kind (cylindrical, rectangular) of closed enclosure. For comparison purposes the vertical temperature distribution of the same storage tank with the same helical tube (Coil III) has been indicated without the flow distributor in Fig. 10. It can be clearly seen what has been earlier mentioned that a strongly mixed temperature field develops inside the tank. 


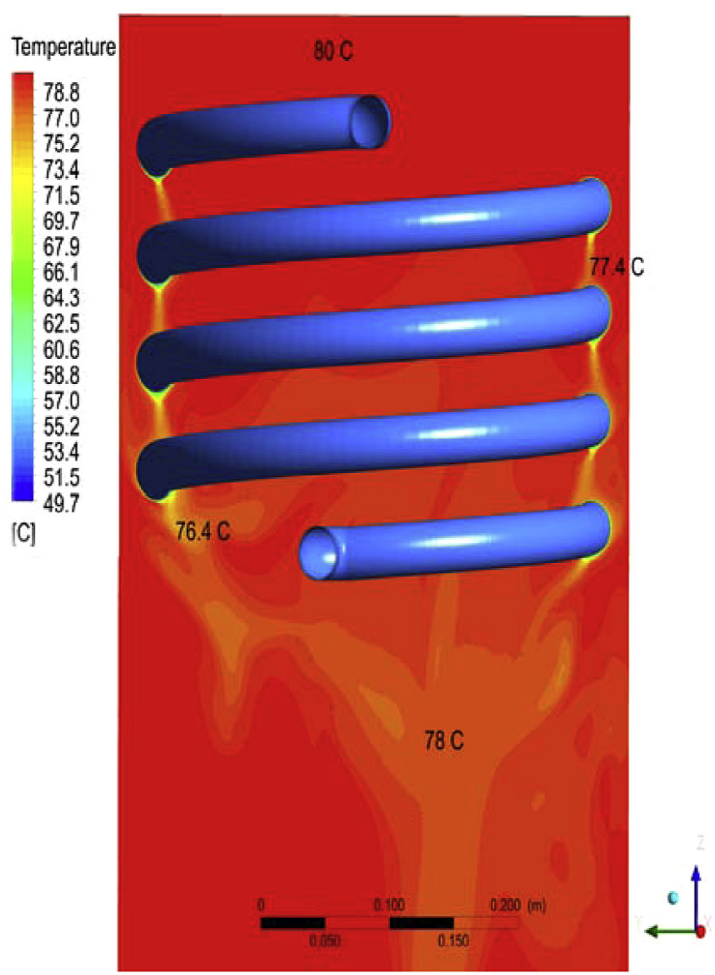

$t=25 \mathrm{~s}$

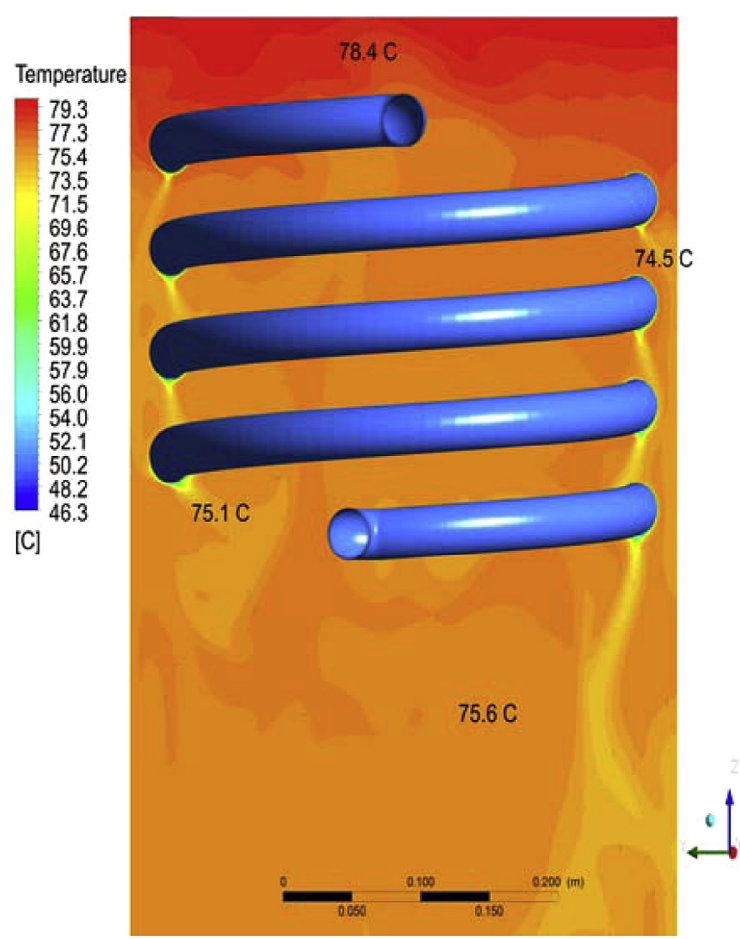

$t=225 \mathrm{~s}$

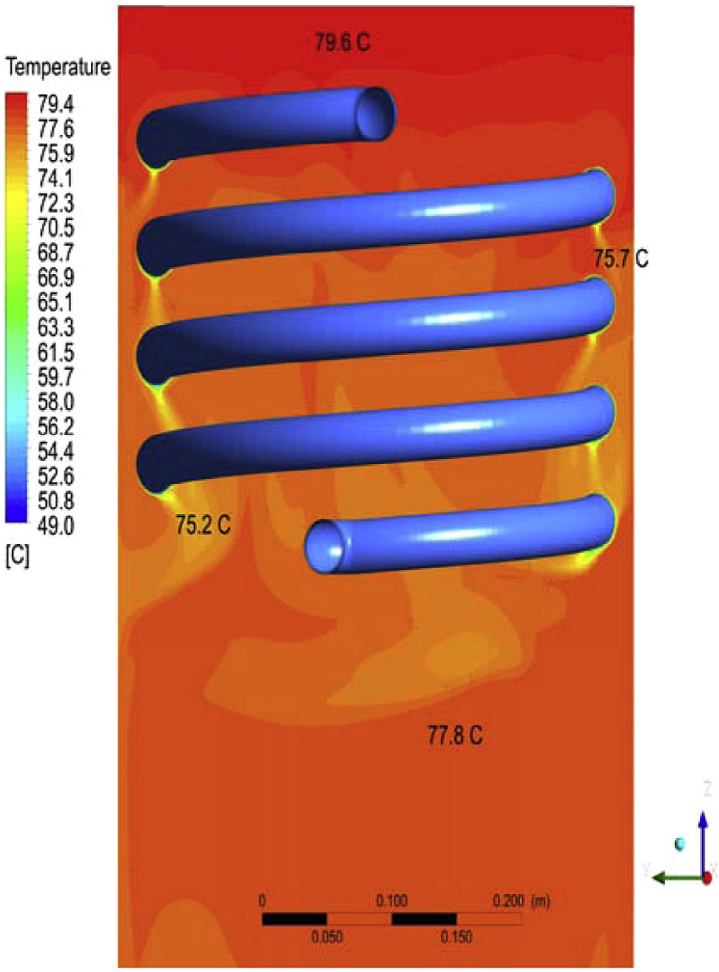

$t=125 \mathrm{~s}$

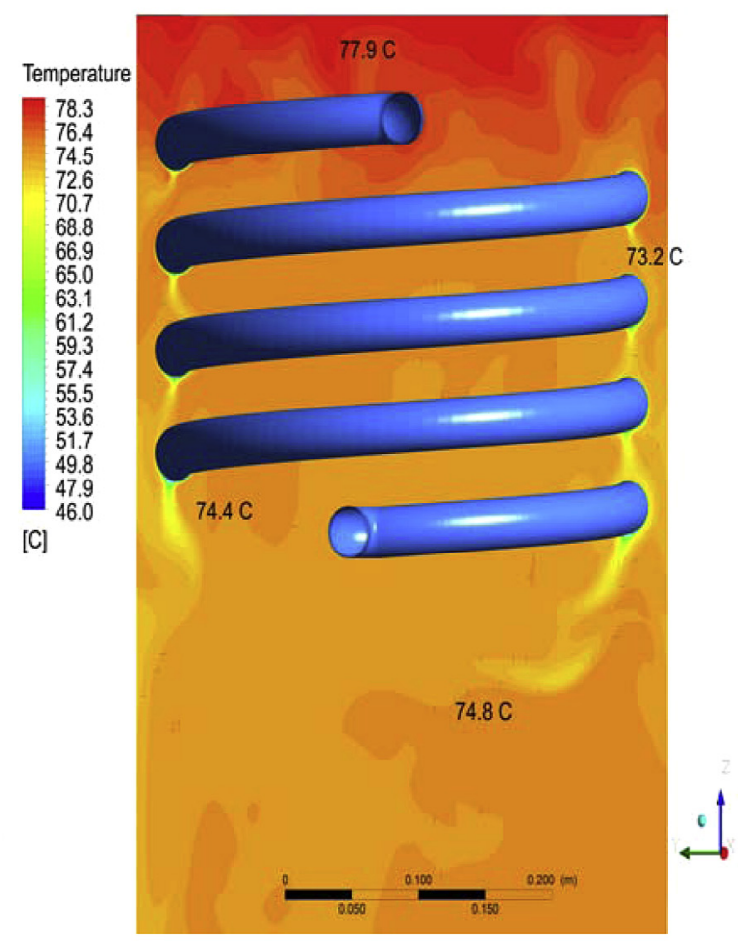

$t=300 \mathrm{~s}$

Fig. 10. Temperature contours at different time instances inside the storage tank (Coil III in case of $T_{\text {in }}=20^{\circ} \mathrm{C}, T_{\text {ini }}=80^{\circ} \mathrm{C}$ ).

3.2. Investigation of the heat transfer process of the coiled tube with and without the flow distributor

The reason of these calculations was to compare the outer side heat transfer intensity of the applied coil (Coil III) operated with and without the helical flow distributor. From that arises the question about how does the helical flow distributor affect the outer side heat transfer rate of the coiled tube heat exchangers. Answering this question several different flow cases have been investigated with the flow distributor - helical coil configuration (FD I with Coil III) applying an unsteady numerical simulation approach to calculate the developing flow and temperature field. In each numerical 
calculations the temperature of the inlet water was constant $\left(20^{\circ} \mathrm{C}\right)$, and the initial temperature of the water inside the cylindrical enclosure has been adjusted to one of the following values $T_{\text {ini }}=\left(40{ }^{\circ} \mathrm{C}\right.$, $\left.60^{\circ} \mathrm{C}, 80^{\circ} \mathrm{C}\right)$ and the applied inlet flow rate of Coil III was $(0.05 \mathrm{~kg} /$ $\mathrm{s})$. The long term evolution of the axial distribution of the outer side Nusselt number has been investigated to answer the arising question. Local peripherally averaged Nusselt number has been calculated at eight different axial positions along the tube axis to compare the heat transfer intensity of the helical coils with and without using the helical flow distributor. Figs. 11 and 12 show the peripherally averaged Nusselt number values along the tube axis for the studied flow distributor configuration. It can be observed from the results that there is no significant alteration between the Nusselt number values at different time instances except at the early transient state where a $30 \%$ larger heat transfer intensity observed along the tube axis as it can be seen in Fig. 12. Fig. 12 shows the axial

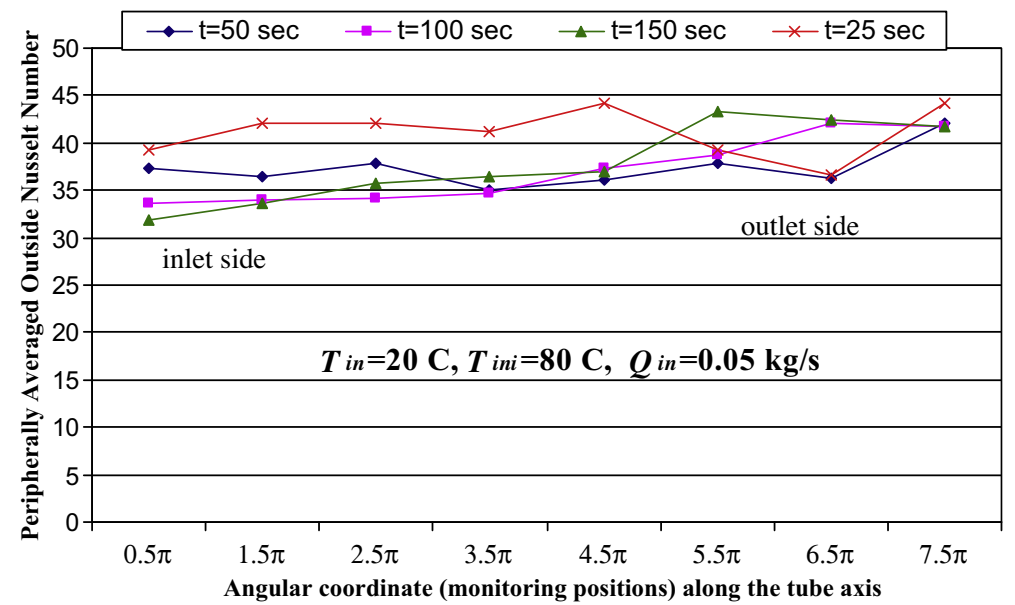

Fig. 11. Peripherally averaged Nusselt number values along the tube axis at different time instances in case of Coil III and FD I flow distributor.

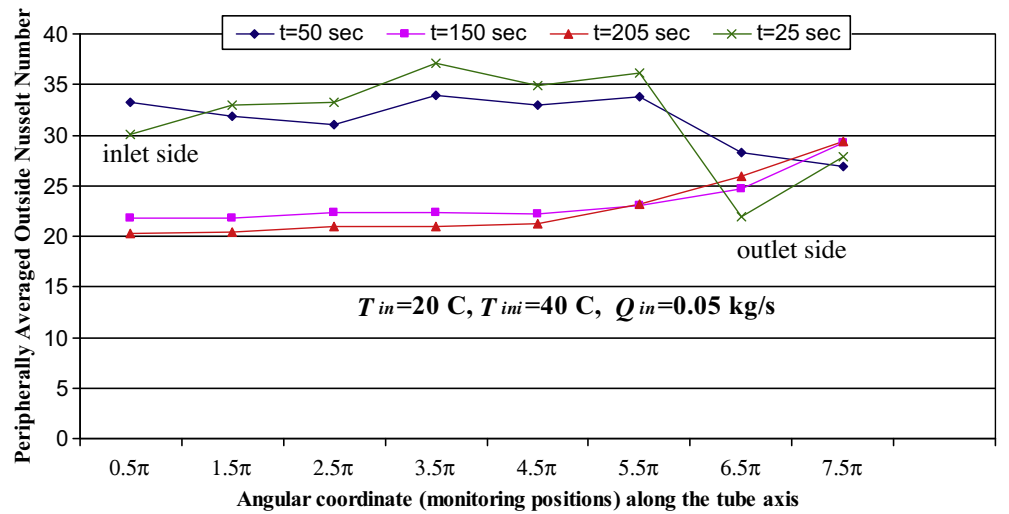

Fig. 12. Peripherally averaged Nusselt number values along the tube axis at different time instances in case of Coil III and FD I flow distributor.

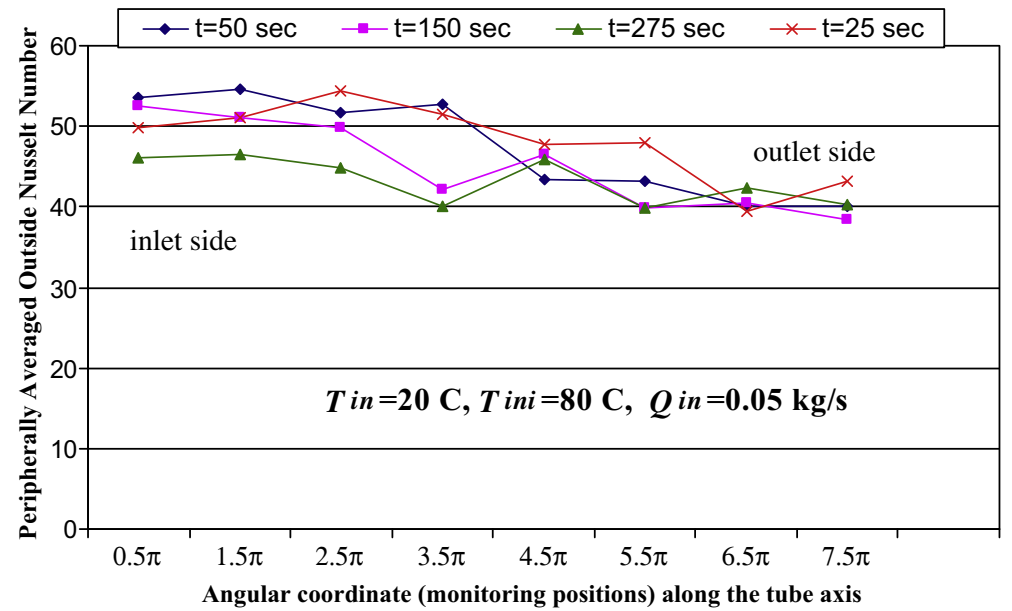

Fig. 13. Peripherally averaged Nusselt number values along the tube axis at different time instances in case of Coil III without a flow distributor. 
distribution of the outer side Nusselt number for FD I flow distributor configuration with a significantly smaller tank initial temperature $\left(T_{i n i}=40^{\circ} \mathrm{C}\right)$. In this case the outer side heat transfer rates much larger in the early transient state than in the fully developed state. The same behavior can be seen in Fig. 11 but in this case the temperature gradient $\left(T_{i n i}-T_{i i}=60^{\circ} \mathrm{C}\right)$ three times larger and the flow process reaches the quasi steady state much faster than in case of $T_{i n i}=40^{\circ} \mathrm{C}$ flow process.

The overall tendency of the axial distribution of the Nusselt number values is small fluctuations around a constant value except near the outlet (last turn) where a $20 \%$ increase can be observed. It can be also concluded from the axial distribution of the Nusselt number values presented in Figs. 11 and 13 that the outer side heat transfer intensity of helical coils is smaller in case of application of a helical flow distributor than the outer side heat transfer rate of uncovered helical coils. The greatest difference has been observed between the heat transfer intensities near the inlet location of the helical pipes and approaching to the outlet this difference fully diminished. This statement is valid for a gap size $\left(d_{\text {gap }}=7 \mathrm{~mm}\right)$ significantly smaller then the outer diameter $\left(d_{\text {out }}=30 \mathrm{~mm}\right)$ of the helical heat exchanger coil. From comparison of Figs. 11 and 13 it can be also concluded that the entire qualitative behavior of the heat transfer intensity shows a stably decreasing pattern toward the outlet in case of uncovered helical coil. If the coil is covered by a helical flow distributor nearly a constant heat transfer intensity can be observed along the tube axis except around last turn where a small increase can be seen.

\section{Conclusions}

A new tube-in-tube helical flow distributor design has been presented and investigated numerically to increase the temperature stratification of closed enclosures operated by any kind of working fluid capable to density stratification. The developed flow and temperature field of the helical flow distributor and the storage tank are examined to gather information about the stratification improvement ability of the flow distributor. Beside this the impact of the flow distributor for the outer side heat transfer rate of the helical heat exchangers are investigated. Different initial storage tank temperatures have been studied to test the impact of flow parameters for the efficiency of the helical flow distributor.

Following general conclusions can be drawn:

1. It can be generally stated that the buoyancy induced velocity field moves downward the cooled fluid along the tube axis of the helically coiled flow distributor. This means that the suggested tube-in-tube helical flow distributor configuration makes it possible to develop a highly stratified temperature distribution inside hot water storage tanks.

2. It can be generally stated that the outer side heat transfer rate of helical heat exchanger coils decreasing covered by a helical tube-in-tube flow distributor. The proper or even an optimal specification of the gap (distance) between the surfaces of helical distributor and the helical coil makes it possible to reach the level of the heat transfer rate of uncovered helical heat exchangers.

3. The suggested tube-in-tube flow distributor configuration makes it possible to apply different heat transfer enhancement tools (different kind of helical corrugations or walls, helical tapes located around the outer surface of the heat exchanger, ...) to increase the outer side heat transfer rate of helically coiled tube heat exchangers covered by the flow distributor.

4. It can be concluded that the outer side local Nusselt number of helically coiled tube heat exchangers covered by a helical flow distributor shows slight irregular oscillations around a mean
Nusselt number value. The axial distribution of the local Nusselt number values shows a slight increasing behavior, near (around the last turn) the outlet. The observed increment is approximately 20\% larger around the last turn of the helical pipe than around the other parts of the helical pipe.

5. Potentially this kind of flow distributor geometry makes it possible to change the buoyancy induced natural convection flow to a forced convection flow over the outer side of the helical coils inserting an electrically operated flow pump somewhere after the inlet location of the collector pipe of the flow distributor to further improve the outer side heat transfer rate of helical coils.

\section{Conflict of interest}

None declared.

\section{Acknowledgements}

This paper was supported by the János Bolyai Research Scholarship of the Hungarian Academy of Sciences. The author would like to thank to János Tóth the reading of the manuscript from mathematical point of view and improving the English language of the text.

\section{References}

[1] K. Warrach, Modelling the thermal stratification in the North Sea, J. Mar. Syst. 14 (1998) 151-165.

[2] P. Ruardij, H. Van Haren, H. Ridderinkhof, The impact of thermal stratification on phytoplankton and nutrient dynamics in shelf seas: a model study, J. Sea Res. 38 (1997) 311-331.

[3] D.G. Kang, M.J. Jhung, S.H. Chang, Fluid-structure interaction analysis for pressurizer surge line subjected to thermal stratification, Nucl. Eng. Des. 241 (2011) 257-269.

[4] H.C. Rezende, A.A.C. Santos, M.A. Navarro, E. Jordão, Verification and validation of a thermal stratification experiment CFD simulation, Nucl. Eng. Des. 248 (2012) 72-81.

[5] H.D. Kweon, J.S. Kim, K.Y. Lee, Fatigue design of nuclear class 1 piping considering thermal stratification, Nucl. Eng. Des. 238 (2008) 1265-1274.

[6] J.A. Duffie, W.A. Beckman, Solar Engineering of Thermal Processes, Wiley, New York, 1980.

[7] K.G.T. Hollands, M.F. Lightstone, A review of low-flow, stratified-tank solar water heating systems, Sol. Energy 43 (2) (1989) 97-105.

[8] E.M. Kleinbach, W.A. Beckman, S.A. Klein, Performance study of onedimensional models for stratified thermal storage tanks, Sol. Energy 50 (1993) 155-166

[9] A. Bouhdjar, A. Benkhelifa, A. Harhad, Numerical study of transient mixed convection in a cylindrical cavity, Numer. Heat Transfer, Part A 31 (3) (1997) 305-324.

[10] Y. Mo, O. Miyatake, Numerical analysis of the transient turbulent flow field in a thermally stratified thermal storage water tank, Numer. Heat Transfer, Part A 30 (7) (1996) 649-667.

[11] M. Benmadda, M. Lacroix, Transient natural convection from a finned surface for thermal storage in an enclosure, Numer. Heat Transfer, Part A 29 (1) (1996) 103-114.

[12] A.J. Ghajar, Y.H. Zurigat, Numerical study of the effect of inlet geometry on stratification in thermal energy storage, Numer. Heat Transfer, Part A 19 (1) (1991) 65-83.

[13] J.H. Davidson, D.A. Adams, Fabric stratification manifolds for solar water heating, Trans. ASME, J. Solar Energy Eng. 116 (1994) 130-136.

[14] Fernandez-Seara Jose, Uhia Francisco J, Sieres Jaime, Experimental analysis of a domestic electric hot water storage tank. Part II: dynamic mode of operation, Appl. Therm. Eng. 27 (1) (2007) 137-144.

[15] N. Altuntop, Z. Kilik, V. Ozceyhan, O. Kincay, Effect of water inlet velocity on thermal stratification in a mantled hot water storage tank, Int. J. Energy Res. 30 (3) (2006) 163-176

[16] B. Zheng, C.X. Lin, M.A. Ebadian, Combined laminar forced convection and thermal radiation in helical pipe, Int. J. Heat Mass Transfer 43 (2000) 10671078.

[17] C.X. Lin, M.A. Ebadian, Developing turbulent convective heat transfer in helical pipes, Int. J. Heat Mass Transfer 40 (1997) 3861-3873.

[18] C.E. Kalb, J.D. Seader, Entrance region heat transfer in a uniform walltemperature helical coil with transition from turbulent to laminar flow, Int. J. Heat Mass Transfer 26 (1983) 23-32.

[19] F. Bozzoli, L. Cattani, S. Rainieri, F.S. Viloche Bazán, L.S. Borges, Estimation of the local heat-transfer coefficient in the laminar flow regime in coiled tubes by 
the Tikhonov regularisation method, Int. J. Heat Mass Transfer 72 (2014) 352361.

[20] J. Fernández-Seara, C. Pineiro-Pontevedra, J.A. Dopazo, On the performance of a vertical helical coil heat exchanger. Numerical model and experimental validation, Appl. Therm. Eng. 62 (2) (2014) 680-689.

[21] S.B. Geniæ, B.M. Jaæimoviæ, M.S. Jariæ, N.J. Budimir, M.M. Dobrnjac, Research on the shell-side thermal performances of heat exchangers with helical tube coils, Int. J. Heat Mass Transfer 55 (2012) 4295-4300.

[22] A. Zachár, Investigation of a new tube-in-tube helical flow distributor design to improve temperature stratification inside hot water storage tanks operated with coiled-tube heat exchangers, Int. J. Heat Mass Transfer 63 (2013) 150161.

[23] D.G. Prabhanjan, G.S.V. Raghavan, T.J. Rennie, Comparison heat transfer rates between a straight tube heat exchanger and a helically coiled heat exchanger, Int. Commun. Heat Mass Transfer 29 (2002) 185-191.

[24] D.G. Prabhanjan, T.J. Rennie, G.S.V. Raghavan, Natural convection heat transfer from helical coiled tubes, Int. J. Therm. Sci. 43 (2004) 359-365.

[25] P.S. Srinivasan, S. Nandapurkar, F.A. Holland, Friction factor for coils, Trans, Inst. Chem. Eng. 48 (1970) T156-T161. 